\title{
Is Talent Management Important? An Overview of Talent Management and the Way to Optimize Employee Performance
}

\author{
Dr. Shadiya Mohamed Saleh Baqutayan \\ Perdana School of Science, Technology and Innovation Policy, \\ University technology Malaysia, Kuala Lumpur campus \\ Email: shadiya@ic.utm.my
}

\section{Doi:10.5901/mjss.2014.v5n23p2290}

\begin{abstract}
In today's global business environment, talent management becomes one important source of competitive advantage that creates value for all companies. Hence, leaders in any organization work very hard to attract, hire, develop and retain talent. Because they believe that people are the only assets that innovate in any organization and innovation is the only path to sustain performance, therefore, managing talent will give some advantage to their company. Furthermore, managing talent must be continuously reviewed, so that the company can capitalize on its talented employees to grow, find the best fit, and expand into new markets. Therefore, talent management needs to be given great effort in every organization and its psychological outcomes need to be debated in order to optimize employee's performance.
\end{abstract}

Keywords: Talent Management; Psychology Outcomes of Talent Management; Optimizing Employee performance

\section{Introduction}

Study about the history of developed countries shows that the role of human capital has been very significant in the development processes of those countries. Human capital has been the important factor of sustainable economic development. Hence, the extent and the level of talent and skilled labors determine the income differences between countries. Furthermore, managing human capital as well as the talent has become one of the most interesting issues and the greatest challenge for policymakers in the field of economy, science, technology and innovation. According to Ashton \& Morton, (2005), an overwhelming number of human resource (HR) practitioners around the world have reported, across various policy studies, that they believe talent management is one of the most important human capital challenges faced by twenty-first century organizations.

Usually any organizations try to have people with the capabilities and commitment needed for current and future organizational success, therefore, they go for talent management. Talent management signifies an organization's efforts to attract, develop, and retain skilled and valuable employees. Hence, before going into more detail let's begin with a clear definition of what talent management is all about. One of the key challenges that scholars have experienced over the past decade has been the unanswered question regarding the definition of talent and talent management. As Lewis \& Heckman (2006), indicated that there is "a disturbing lack of clarity regarding the definition, scope and overall goals of talent management". This might be one reason why practitioners find its realization quite challenging but nonetheless extremely important for the company's future (DGFP, 2009). Therefore, a concrete and clear definition of talent and talent management need to be constructed as a continuous guide to organization.

\section{Who is the Talented in the Organization and How do we Manage them?}

In literature, several definitions for both talent and talent management exist, but how much it can be applicable to employees at different organization is another question. After having discussed several definitions, the following definition of talent is more applicable to the researcher understanding of this paper. It is stated by DEA (2009), "a talent is an individual with special competencies. In a business or other context, these competencies are of strategic importance to the organization. The absence of these competencies would pose an actual situation of crisis for the organization." In addition to that, "Talent consists of those individuals who can make a difference to organizational performance either through their immediate contribution or, in the longer-term, by demonstrating the highest levels of potential" (CIPD, 2012). 
Based on the above, every organization should have the quantity and quality of people in place to meet their current and future business priorities (Wellins, et al 2012). Consequently, all employees are talented because they have the skills, capacity or/and the capabilities that are important to their organizations. In respect to the individual differences, employees might have the skills in specific area that can be considered as being talent in that particular part. Therefore, talented indeed can be found anytime and anywhere throughout the whole organization. But then they need someone to manage their abilities, so that the organization will not be losing the performance and competitive advantages of those talented employees.

Hence, "talent management" is another term that needs to be explained at this particular point. The term "talent management" is still somewhat of a mystery to most, but it is becoming more widely used to describe the overall HR strategy around people in the workplace. And just like reliability is becoming a more recognized and appreciated component to gaining a competitive advantage in manufacturing, best-practice organizations have identified talent management as the key component of their business strategy to differentiate themselves from the competition and achieve desired goals ( $\mathrm{Ha}, 2006)$.

According to CIPD (2012), "Talent management is the systematic attraction, identification, development, engagement, retention and deployment of those individuals who are of particular value to an organization, either in view of their 'high potential' for the future or because they are fulfilling business/operation-critical roles"

In the broadest sense, it is "the strategic management of the flow of talent through an organization" (Paquet \& Rogers, 2008, p.1) and could help an organization to "align the right people with the right jobs at the right time based on business priorities" (Paquet \& Rogers, 2008, p.1). It can also be defined as a holistic and strategic approach to human resource and business planning, or as a new way to increase organizational effectiveness. Its first goal is to improve the potential of employees who are seen as able to make a valuable difference for the organization, now or in the future. The other goal is to satisfy the employee and make them enjoy working in the job that suite their skills and competencies.

People are increasingly valuable source of sustainable competitive advantage for organizations, therefore, getting and keeping the right people in the right places at the right time has never been challenging, in fact, that is the way of talent management approach.

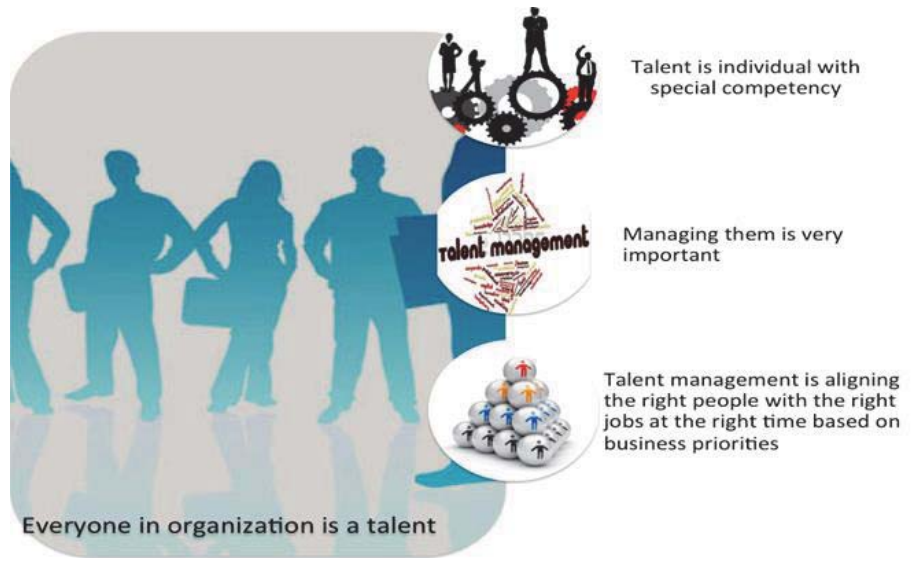

Figure 1: Talent and Talent Management

\section{What does Talent Means to your Organization?}

Literature on the above discussion is tending one to believe on the importance of talent management in any organization. According to Bersin, (2006), talent Management is a powerful and important trend across Human Resource. It changes the way employees are organized, how they use technology, how they resources are allocated, and how they measure what they do.

In study done by Richard et al (2011) evidently explain the need for talent management is a strong plea for better business performance. Psychologically, when the employee is placed in the right position surely he/she will have a better business outcome. The Process Perspective focuses on practices needed to optimize workers' accomplishments within organizations. The core belief is that future success depends on an organization having an appropriate process for talent to achieve its potential. 
In a competitive marketplace, talent management is a primary driver for organizational success. According to PMI (2013), the level of talent management alignment to organizational strategy has a clear impact on the success of projects meeting their original goals and business intent. Organizations in which talent management is aligned to organizational strategy have an average project success rate of $72 \%$ per cent, while organizations in which talent management is not effectively aligned to organizational strategy have an average project success rate of $58 \%$ per cent. The difference of $14 \%$ percentage points in project success rates equates to risking $50 \%$ per cent more project dollars when talent management is not effectively aligned with strategy.

Research shows that organizations increasingly focus on talent management, because the implementation of a talent management process is expected to create an environment for people to develop their skills in preparation for a range of future possibilities thereby preparing the workplace for changing roles (Innovation \& Growth, 2013). Thus, systems should be put in-place that enables talented individuals to excel and develop successful careers as well as positive working environment within the organization. Moreover, talented people will thrive and progress if they meet the competency and performance requirements of the talent management process (Blass, 2007). Eventually, talent management is positively relates to job performance (Elsalanty, 2011).

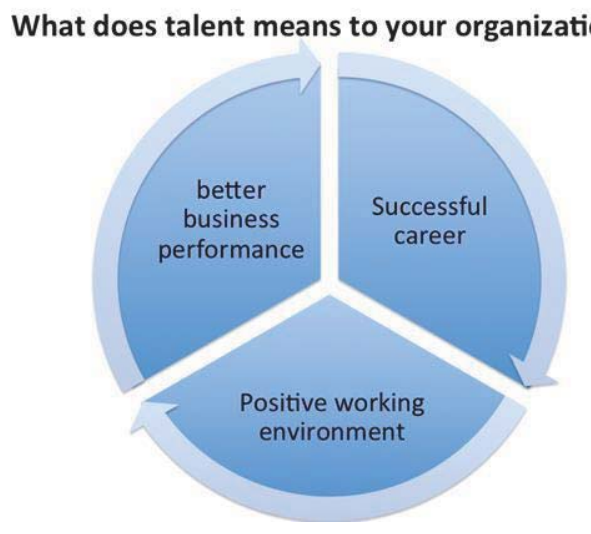

Figure 2: Talent Management and Organization

\section{How Talent can be Managed?}

After all, talent management not only requiring keeping the right people in the right positions, but also requires some process as psychological contracts, career paths, and talent-culture. In Businessballs.com (2010) the psychological contract stated on Wikipedia, April 2010 as: "the mutual beliefs, perceptions, and informal obligations between an employer and an employee. It sets the dynamics for the relationship and defines the detailed practicality of the work to be done". This is considered very important in talent management because it will help the talented employee to know what they desire and what drives them in their work.

Psychological contract is the key factor to influence the talented employees' commitment and turn over intention. The psychological contract is build upon perceived employer and employee obligations and is good indicators of the status of the employment relationship employees have with the organization. Accenture and Tilburg (2009) studied the effectiveness of Talent Management practices and their impact on the employment relationship in terms of psychological contracts. The outcome indicated that talents experience less psychological contract violation and non- talents experience more psychological contract violation. Though this outcome does not support our objectives, but we strongly support the idea that talent management can be through keeping them in the organization and giving them their rights through what is written in the psychological contract.

While, career path is another process in managing talented, according to the MBA School (2013), that career path is "the growth of the employee in an organization". In another word: "the various positions an employee moves to as he/she grows in an organization". Indeed, talented employees need room to grow-both locally and as part of the global enterprise. Effectively managing top talent in emerging markets often requires organizational structures and career paths that are aligned to cultural values while still part of a global framework (Morrison, et al., 2013).

Many studies showed direct correlation between company success and a work culture that fosters creativity and talent. Talent-culture is: "the values, beliefs, behaviors, and environment required to attract, engage, and retain 
committed and competent employees" (Aguirre, et al, 2009). According to Allen \& Doladee (2011), many successful companies have unique ways of motivating employees. Ultimately, creating a talent-rich organization isn't rocket science and doesn't have to be an expensive endeavor. All that's required is a culture that motivates and excites employees so that talent is continually refreshed and sustained throughout the life of the company.

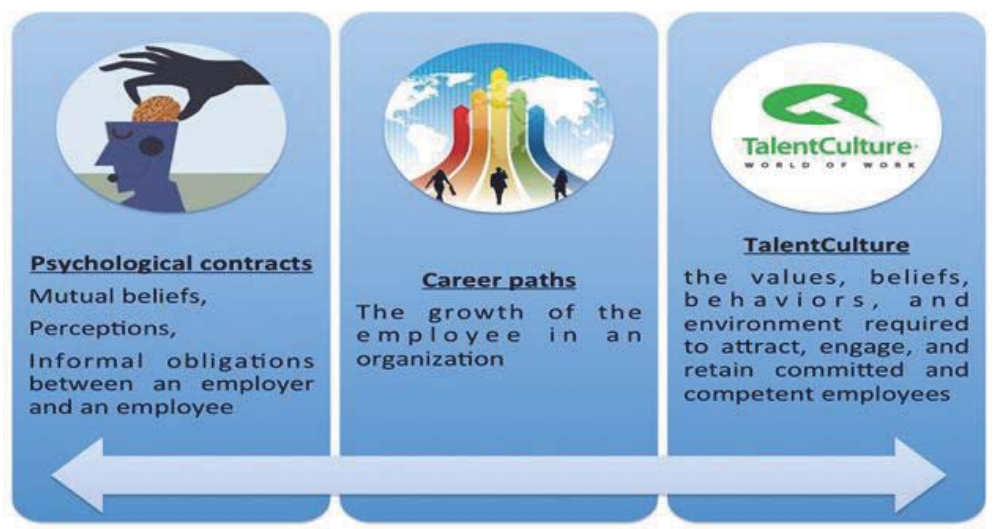

Figure 3: Talent Management process

\section{The Psychological Outcomes of Talent Management}

Several outcomes of talent management were underlined in different research, but what is the psychological outcome of the talent management is another question that need to be answered. Kahn W.A. highlighted the linking of psychological matters to human capital management in 1990. He found that desirable outcome could be expected if psychological meaningfulness and psychological safety exist, and when the employees themselves were more psychological available (Bux \& Tay, 2010).

One psychological outcome that needs to be considered among talented employee is "innovation" competence. As a matter of fact, innovation is key to a company's success; it has been stated so frequently that it should go without saying. However, less discussed on how and where talent management fits into innovation. Past research by Lichtenberg, Woock, \& Wright, (2008) had confirmed that having the right talent in the right position is essential for creating and maintaining a culture of innovation. What is more is that innovative ideas and innovative products are the essential of talent management outcomes at any organization; furthermore, the innovator groups of talented employees are always motivated by their inner and psychological drive to propose new ideas and solutions to solve organizational problems. This motivational drive energize talented to look into their work from broader angle that later on persuade them to have better psychological outcomes (McCartney, 2009).

The assessment of emotional intelligence competencies began as curiosity about talent (McClelland, Baldwin, Bronfenbrenner, \& Strodbeck, 1958). Emotional intelligence (EI) is a convenient phrase with which to focus attention on the underlying emotional components of human talent. In another word, ability of talented to identify, assess, and control their emotion. Therefore, emotional intelligence affects the development of talent. For instance, Kram \& Cherniss (2010) showed how the emotional intelligence of the mentor, boss, or peer would influence the potential of a relationship with that person for helping organizational members develop and use the talent that is crucial for organizational effectiveness. At this point, talent management is very important, and the emotional intelligent of the talent need to be taken into consideration as psychological outcomes for talent management.

Another psychological outcome among talented is developing communication and teamwork skills. Talented employees showed their ability to demonstrates in teamwork performance, furthermore, they shows positive interactions with coworkers, communicate clearly and efficiently, demonstrates compromise, cooperation, and interpersonal understanding in teams, and displays positive attitudes about work and the organization. This is because they are in their right position at the organization and they are expert in the job they are practicing. Therefore, they are motivated to show their talent and ability to others, through participating on group and teamwork.

Furthermore, talented employee also develops a positive mindset, as well as behavioral attitudes of selfconfidence and self-esteem. According to McKinsey (2001, p. 4): "a talent mindset is the deeply held belief that build a strong management talent pool to achieve the aspirations of the company. Leaders with a talent mindset roll up their 
employees and make talent their job." In conclusion and after having reviewed the above studies, the following outcomes gathered from different sources, and viewed as more applicable diagram to the psychological outcomes of talent management of this research. These are as followed:

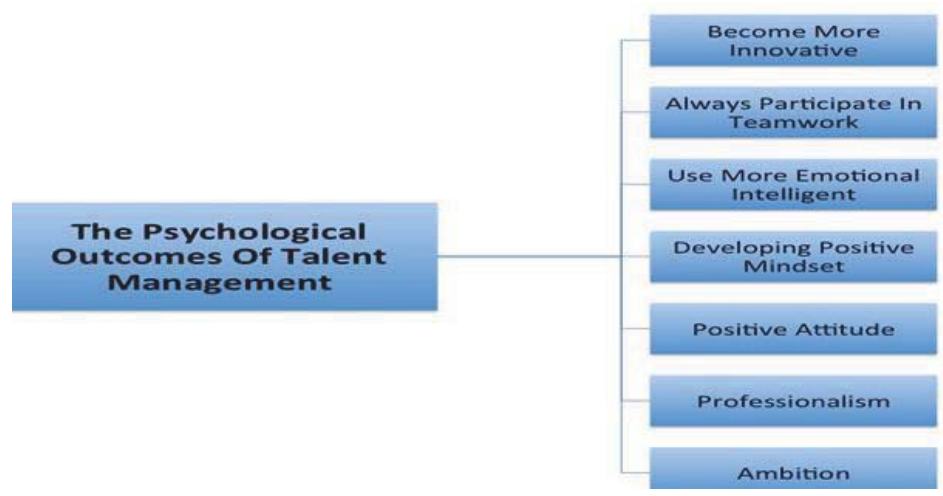

Figure 4: The Psychological Outcomes of Talent Management

\section{Conclusion}

Based on the above, it can be concluded that talent management is of importance to employees, and should be of importance to the organization as well because it can lead to a competitive advantage to all employees. But what is more important at this particular moment is to give a clear explanation of what talent is and how it can be managed, as readers are not clear of the exact meaning of talent and talent management, this research made it clear to everybody. Therefore, we conclude that talented can be anyone, it can be you, he, she, or me. As they all run the organization, and they determine the success of that organizations. So, talent management is management of the people or employees themselves by retaining the right individuals, for the right positions, at the right time.

\section{Acknowledgement}

I would like to acknowledge and extend my heartfelt gratitude to The Ministry of Education and Universiti Teknologi Malaysia for the financial assistance in funding this research. My sincere thank to all my colleagues who kindly provided valuable and helpful comments of this paper.

\section{References}

Accenture and Tilburg (2009). How effective are Talent Management practices. Retrieved on 2 September 2014, From: http://www.accenture.com/nl-en/Documents/PDF/Accenture_TMreport_A4_Brochure.pdf

Aguirre, et al (2009). Global Talent Innovation Strategies for Breakthrough Performance. Printed in USA๑2009 Booz \& Company Inc. Retrieved on 13 August, 2014, from: http://www.google.com.my/url?sa=t\&rct=j\&q=\&esrc=s\&source=web\&cd=4\&ved=0CEw QFjAD\&url=http\%3A\%2F\%2Fwww.booz.com\%2Fmedia\%2Ffile\%2FGlobal_Talent_Innovation.pdf\&ei=9y4xUvffLYeRrAf7YD4DA\&usg=AFQjCNEwhTq-ir0OY2SXG7VxwIn5Spz93g\&sig2=f7AczZ9IdSGG1fR75eeUxoA

Allen, E., \& Doladee, B. (2011). Culture: If you build it (right), the talent will come (and stay). Retrieved on 2 September 2014, From: http://mc.manuscriptcentral.com/jcdc

Ashton, C., \& Morton, L. (2005). Managing talent for competitive advantage. CRF Publishing, 4(5), $28-31$.

Blass, Eddie. (2007) Talent management: Maximising Talent for business performance, Chartered Management Institute/Ashridge Consulting.

Bersin, J. (2006). Talent Management: What is it? Why now? Retrieved on 28 August, 2014, From: http://www.bf.umich. edu/docs/KeyReferenceArticles.pdf

Businessballs.com (2010). The psychological contract: he theory of psychological contracts in organizational employment-and wider 'psychological contracting' in relationships, communications and societies - and the psychological contract 'iceberg' diagram. Retrieved on 13 September 2013, from: http://www.businessballs.com/psychological-contracts-theory.htm

Bux, S. R. \& Tay, A. (2010). The Relationship of Psychological Empowerment, Talent Engagement and Talent Outcomes. International Review of Business Research Papers Vol.6, No.1 February 2010, Pp.215-227

CIPD, (2012). Talent management: An Overview Resource summary. Retrieved on 27 August, 2014, from: http://www.cipd.co.uk/hr- 
resources/factsheets/talent-management-overview.aspx

DEA. (2009). Project description. DEA: Copenhagen, Denmark.

Deutsche Gesellschaft für Personalfuihrung e.V. [DGFP] (2009, September 06). Länderbericht Deutschland. 42. Dreiländertreffen. Jongny s/Vevey (Schweiz).

Elsalanty, L. E. (2011). The Mediating Methods of Leadership Development in the Relationship between Talent Management and Job Performance. International Journal of Innovation \& Human Resources Management Vol 1 No 1 Dec 2011.

Ha, J., (2006). Talent management: what's it mean? Retrieved on 27 August, 2014, from: http://www.reliableplant.com/Read/1632/talentmanagement

Innovation \& Growth, (2013). Talent Management: Process Guide. Retrieved on 2 September, 2014, from: http://novascotia.ca/psc/pdf/ hrCentre/resources/talentManagement/TM_Process_Guide.pdf

Kram, K. E., \& Cherniss, C. (2001). Developing emotional competence through relationships. In C. Cherniss \& D. Goleman (Eds.), The emotionally intelligent workplace: How to select for, measure, and improve emotional intelligence in individuals, groups, and organizations: 254 -285. San Francisco: Jossey-Bass.

Lewis, R. E., \& Heckman, R. J. (2006). Talent management: A critical review. Human Resource Management Review, 16, $139-154$.

Lichtenberg, J., Woock, C., \& Wright, M., (2008). Ready to Innovate: Are Educators and Executives Aligned on the Creative Readiness of the U.S. Workforce? Retrieved on 12 September, 2013, from: http://www.artsusa.org/pdf/information_services/research/ policy roundtable/readytoinnovatefull.pdf

MBA School (2013). Career Path Concept. Retrieved on 14 September 2013, from: http://www.mbaskool.com/businessconcepts/human-resources-hr-terms/1782-career-path.html

McCartney, C. (2009). Fighting Back Through Talent Innovation, Talent Management Under Threat In Uncertain Times. Retrieved on 10 September 2013, from: http://www.cipd.co.uk/NR/rdonlyres/D5B7809A-FBF0-489D-BB73-26C0C3C7B194/0/Fighting_back_ through_talent_innovation.pdf

McClelland, D.C. ., Baldwwin, A.L., Bronfenbrenner, U., \& Strodbeck, F.L. (1958). Talent and society: new perspectives in the identification of ta- lent. Princeton, NJ: D. Van Nostrand.

McKinsey \& Co. (2001). The war for talent: organizational and leadership practices. April, 1-9.

Morrison, T., et al., (2013). Emerging Market Talent Strategies: Creating an effective global talent model. Retrieved on 2 September, 2014, from: http://dupress.com/articles/emerging-market-talent-strategies/

Paquet, S., \& Rogers, K. (2008). A talent management framework that will raise your organization's game to the next level. Perspective Magazine.

PMI, (2013). The Competitive Advantage Of Effective Talent Management. Retrieved on 2 September, 2014, from: http://www.pmi.org/ /media/PDF/Business-Solutions/PMExecutiveSummaryTalentMgmt.ashx

Richard, S. W., Audrey, B. S., \& Scott E., (2011). Nine best practices for effective talent management. Development Dimensions International Inc. white paper available online at http://www.ddiworld.com

Wellins, R. S., et al (2012). Nine Best Practices For Effective Talent Management. Retrieved on 25 August 2014, from: https://www.ddiworld.com/DDIWorld/media/white-papers/ninebestpracticetalentmanagement_wp_ddi.pdf?ext=.pdf 